Vol.3 No.1 Hal. 16 - 22

Juni 2020

\title{
Aspek Religi-Edukatif Pemahaman Ibadah Mu'amalah Melalui Penerapan Model Pembelajaran U.G.L Di Kelas III SDN 064969 Kecamatan Medan Tembung Pada Semester I T.P. 2018/2019
}

\author{
Sri Wahyuningsih \\ SDN 064969 Kecamatan Medan Tembung \\ Sriwahyun005@gmail.com
}

\begin{abstract}
ABSTRAK
Penelitian ini adalah penelitian tindakan kelas dengan tujuan adalah sebagai bentuk pendekatan Up Grading Learning Model Kooperatif dalam pembelajaran Agama Islam agar datap meningkatkan hasil belajar siswa, mengetahui apakah menggunakan pendekatan Up Grading Learning model kooperatif dapat meningkatkan hasil belajar Kelas III SDN 064969. Dari hasil kuis pertama nilai yang diperoleh belum maksimal, karena dari 25 Siswa yang mendapatkan nilai diatas 65 sebanyak 15 siswa (68.18\%). Ini berarti dari pembelajaran siklus pertama 15 siswa yang tuntas belajarnya. Dan dalam 4 kelompok yang ada, hanya 3 kelompok yang berhak mendapat predikat, yaitu kelompok 1 dengan predikat hebat, kelompok 3 dan kelompok 4 dengan predikat baik sedangkan kelompok 2 dan kelompok 5 tidak mendapat predikat. Pada siklus kedua aktivitas guru pada pendahuluan sebanyak 17\%. Pada tahap ini guru memberi beberapa pertanyaan apersepsi tentang perubahan materi yang telah dipelajari sebelum nya. Guru juga memberi informasi dan instruksi tentang eksperimen yang dilakukan pada hari tersebut, serta mengingatkan kelompok untuk bekerja lebih maksimal agar mendapat penghargaan Aktivitas yang dominan tetap guru menjelaskan materi/mendemontrasikan ketrampilan $(22,10 \%)$ dan memeriksa pemahaman siswa dan mem berikan umpan balik bagi siswa yang bertanya dan mengklarifikasi materi yang kurang jelas (15.75\%). Pada siklus ketiga sikap yang negatif tersebut sudah tidak tampak. Diakhir pembelajarn guru memberikan kuis untuk mengukur prestasi belajar siswa. Pada siklus ini tampak bahwa prestasi belajar siswa meningkat cukup tajam, dari siklus pertama yang tuntas 15 siswa $(68.18 \%)$ siklus kedua 18 siswa $(81.82 \%)$ meningkat menjadi 20 siswa $(90.91 \%)$ pada siklus ke tiga.
\end{abstract}

Kata Kunci : Penelitian Tindakan Kelas, Aspek Religi Edukatif, Model Pembelajaran UGL, Siklus

\begin{abstract}
This research is a classroom action research with the aim is as a form of the Up Grading Learning Model Cooperative Learning in Islamic learning so that it can improve student learning outcomes, find out whether using the Up Grading Learning cooperative approach can improve the learning outcomes of Class III SDN 064969. From the results of the first quiz the value obtained is not optimal, because of the 25 students who score above 65 are 15 students (68.18\%). This means that from the first cycle of learning 15 students who have finished learning. And in the 4 groups that exist, only 3 groups are entitled to the title, namely group I with a great predicate, group 3 and group 4 with a good predicate while group 2 and group 5 do not get the title. In the second cycle of teacher activity in the preliminary as much as $17 \%$. At this stage the teacher gives some apperception questions about changes in material that has been studied before it. The teacher also gives information and instructions about the experiments conducted on that day, and reminds the group to work more optimally in order to get a dominant activity. The teacher continues to explain the material / demonstrate the skills $(22.10 \%)$ and check student understanding and provide feedback for students who ask and clarify material that is less clear (15.75\%). In the third cycle the negative attitude is not visible. At the end of the lesson the teacher gives a quiz to measure student achievement. In this cycle it appears that student achievement has increased quite sharply, from the first cycle that was completed 15 students $(68.18 \%)$ the second cycle 18 students $(81.82 \%)$ increased to 20 students $(90.91 \%)$ in the third cycle.
\end{abstract}

Keywords : Classroom Action Research, Educational Religious Aspects, UGL Learning Models, Cycles 
Wahyuningsih S : Aspek Religi-Edukatif Pemahaman Ibadah Mu'amalah Melalui Penerapan Model Pembelajaran U.G.L di Kelas III SDN 064969 Kecamatan Medan Tembung Pada Semester I T.P. 2018/2019

\section{PENDAHULUAN}

\section{Latar Belakang}

Pelaksanaan pembelajaran di dalam kelas merupakan salah satu tugas utama guru, dan pembelajaran dapat diartikan sebagai kegiatan yang ditujukan untuk membelajarkan siswa. Dalam proses pembelajaran masih sering ditemui adanya kecenderungan meminimalkan keterlibatan siswa. Dominasi guru Agama Islam dalam proses pembelajaran Agama Islam di kelas, menyebabkan kecenderungan siswa lebih bersifat pasif sehingga mereka lebih banyak menunggu sajian guru daripada mencari dan menemukan sendiri pengetahuan, ketrampilan atau sikap yang mereka butuhkan. Salah satu model pembelajaran yang dapat dilaksanakan di dalam kelas untuk mengaktifkan siswa belajar adalah pembelajaran melalui pendekatan Up grading Learning. Pembelajaran Up grading Learning menekankan pada menghubungkan mata pelajaran dengan situasi dunia nyata dan pembelajaran yang memotivasi siswa agar mampu menghubungkan pengetahuan dan terapannya dengan kehidupan sehari-hari sebagai anggota keluarga dan masyarakat. Dari kegiatan pembelajaran yang demikian ini, diharapkan dapat mendorong munculnya lima bentuk cara belajar siswa; (1) siswa dapat menghubungkan situasi sehari-hari dengan informasi yang diserap; (2) siswa dapat menemukan sendiri konsep-konsep baru; (3) siswa dapat menerapkan konsep dan informasi di depan; (4) siswa dapat mengkoordinasikan konsep dan informasi yang diperoleh dengan pelajaran; dan (5) siswa dapat menstransfer konsep dan informasi yang dimiliki kepada pelajar lain. Dari uraian di atas yang menjadi permasalahan, selama ini proses pembelajaran Agama Islam yang ditemui masih secara konvensional, seperti ekspositori, drill atau ceramah. Proses ini hanya menekankan pada pencapaian tuntutan kurikulum dan penyampaian tekstual semata daripada mengembangkan kemampuan belajar dan membangun individu. Kondisi seperti ini tidak akan menumbuh kembangkan aspek kemampuan dan aktivitas siswa seperti yang diharapkan. Akibatnya nilai-nilai yang didapat tidak seperti yang diharapkan. Dalam hal ini guru ingin memperbaiki keadaan tersebut dengan mencobakan suatu strategi pembelajaran yang belum pernah dilaksanakan, yaitu pendekatan pembelajaran yang akan membuat siswa dapat belajar aktif dimana siswa lebih berpartisipasi aktif sehingga kegiatan siswa dalam belajar jauh lebih dominan dari pada kegiatan guru dalam mengajar.

\section{Perumusan Masalah}

Berikut ini dikemukakan rumusan masalahnya sebagai berikut :

1. Apakah pendekatan Up grading Learning model kooperatif dalam pembelajaran Agama Islam pada pokok bahasan Ibadah Mu'amalah dapat meningkatkan aktivitas belajar siswa di kelas III SDN 064969 Kecamatan Medan Tembung Pada Semester 1 T.P.2018/2019?

2. Apakah peningkatan aktivitas belajar dengan menggunakan pendekatan Up grading Learning model kooperatif dalam pembelajaran Agama Islam dapat meningkatkan aktivitas belajar siswa di kelas III SDN 064969 Kecamatan Medan Tembung Pada Semester 1 T.P.2018/2019? 
Wahyuningsih S : Aspek Religi-Edukatif Pemahaman Ibadah Mu'amalah Melalui Penerapan Model Pembelajaran U.G.L di Kelas III SDN 064969 Kecamatan Medan Tembung Pada Semester I T.P. 2018/2019

\section{Tujuan Penelitian}

Sesuai dengan rumusan masalah di atas, maka penelitian ini bertujuan :

1. Untuk mengetahui pendekatan Up grading Learning model kooperatif dalam pembelajaran Agama Islam dapat meningkatkan hasil belajar siswa Kelas III SDN 064969 Kecamatan Medan Tembung Pada Semester 1 T.P.2018/2019.

2. Untuk mengetahui peningkatan aktivitas belajar dengan menggunakan pendekatan Up grading Learning model kooperatif dalam pembelajaran Agama Islam di kelas III SDN 064969 Kecamatan Medan Tembung Pada Semester 1 T.P.2018/2019

\section{Manfaat Penelitian}

Penelitian tindakan kelas ini diharapkan dapat memberikan manfaat bagi berbagai pihak, antara lain :

1.Sebagai sarana peneliti untuk mengembangkan pengetahuan ketrampilan, dan wawasan berpikir kritis guna melatih kemampuan memahami dan menganalisa masalah-masalah pendidikan secara sistematis dan konstruktif.

2. Memberikan masukan kepada guru Agama Islam sebagai bahan pertimbangan dalam meningkatkan kegiatan belajar mengajar.

3. Memberikan motivasi siswa dalam berpikir kritis, kreatif, dan inovatif untuk meningkatkan prestasi belajar Agama Islam .

\section{METODE PENELITIAN \\ Pendekatan dan Jenis Penelitian}

Pendekatan yang digunakan dalam penelitian ini adalah pendekatan kualitatif. Jenis penelitian yang digunakan adalah penelitian tindakan kelas (PTK). Penelitian dirancang dalam bentuk siklus tindakan. Dalam siklus tindakan terdiri atas empat kegiatan, yakni rencana tindakan, pelaksanaan, pengamatan, dan refleksi. Penelitian dilaksanakan dalam tiga siklus. Siklus 1 dilaksanakan pada bulan Juli, siklus 2 dilaksanakan pada bulan Agustus, dan siklus 3 dilaksanakan pada bulan September.

\section{Lokasi dan Subyek Penelitian}

Penelitian dilaksanakn di SDN 064969 Kecamatan Medan Tembung Pada Semester 1 T.P.2018/2019. Subyek penelitian adalah seluruh siswa kelas III sebanyak 22 Siswa.

\section{Sumber Data penelitian}

Sumber data yang diperoleh dalam penelitian ini adalah :

1. Siswa, tentang aktivitas belajar siswa dalam pembelajaran Agama Islam melalui pendekatan Up grading Learning di Kelas III SDN 064969 Kecamatan Medan Tembung Pada Semester 1 T.P.2018/2019.Guru

2. Agama Islam, tentang aktivitas guru Agama Islam dalam pengelolaan pembelajaran Agama Islam melalui pendekatan Up grading Learning di Kelas III SDN 064969 Kecamatan Medan Tembung Pada Semester 1 T.P.2018/2019.

3. Dokumen tentang nilai hasil belajar siswa 
Wahyuningsih S : Aspek Religi-Edukatif Pemahaman Ibadah Mu'amalah Melalui Penerapan Model Pembelajaran U.G.L di Kelas III SDN 064969 Kecamatan Medan Tembung Pada Semester I T.P. 2018/2019

\section{Teknik Pengumpulan data dan Teknik Analisis Data}

Kegiatan pengumpulan data dilakukan dengan menggunakan instrumen penelitian: pengamatan (observasi), catatan lapangan, dan dokumen tasi. Pengamatan difokuskan pada pelaksanaan pembelajaran Agama Islam melalui pendekatan kontekstual Catatan lapangan dilakukan dengan mencatat peristiwa nyata yang terjadi dalam kegiatan belajar mengajar baik secara diskriptif maupun reflektif. Dokumentasi berupa kegiatan mendokumen data verbal tertulis dan foto. Analisis data dilakukan dengan menggunakan teknik analisis data kualitatif yang bersifat linear (mengalir) yang didalamnya melibatkan kegitan penelaahan seluruh data yang telah dikumpulkan, reduksi data (didalamnya terdapat kegiatan pengkategorian dan pengklasifikasian) dan verifikasi, serta penyimpulan data. Penentuan keberhasilan tindakan didasarkan pada dua tinjauan, yakni proses belajar dan hasil belajar. Penentuan keberhasilan proses didasarkan pada diskriptor kualifikasi terhdap aktivitas belajar siswa, sedangkan penentuan keberhasilan hasil belajar ditentukan melalui ulangan harian.

\section{HASIL DAN PEMBAHASAN \\ l. Perencanaan}

Perencanaan tindakan meliputi kegiatan menyusun rencana pem belajaran (RP) atau skenario pembelajaran melalui pendekatan Up grading Learning. Sebagai pendamping guru Agama Islam menggunakan lembar kegiatan siswa (LKS) yang menekankan pada aktivitas mengamati, menganalisis, menyimpulkan, dan mengkomunikasikannya kepada teman sebaya. Membuat lembar observasi untuk memantau kegiatan pembelajaran, membuat alat evaluasi untuk mengetahui keberhasilan belajar siswa.

\section{Pelaksanaan}

Pada pelaksanaan tindakan ini, guru Agama Islam mensosialisasikan pembelajaran Agama Islam melalui pendekatan Up grading Learning sebagaimana tergambarkan pada rencana pembelajaran (RP). Saat berlangsungnya kegiatan belajar mengajar, guru Agama Islam membagi kelas menjadi beberapa kelompok dan setiap kelompok beranggotakan 5 siswa secara heterogin, guru menyajikan/menyampaikan materi pembelajaran, guru Agama Islam memberi tugas kepada kelompok untuk dikerjakan, anggota kelompok yang sudah menguasai diminta menjelaskan pada anggota kelompoknya sampai anggota dalam kelompok itu mengerti atau memahami, guru berkeliling membimbing, mengawasi, dan langsung menilai proses pembelajaran terhadap siswa, sete1ah selesai, lewat juru bicara mempresentasikan hasil pembahasan di kelompoknya, kelompok lain dapat memberikan tanggapan terhadap hasil pembahasannya, guru Agama Islam memberikan penjelasan (klarifikasi) bila terjadi kesalahan konsep dan memberikan kesimpulan, pada akhir pertemuan diadakan evaluasi.

\section{Observasi}

Selama berlangsungnya kegiatan belajar mengajar, observasi dilaksanakan secara kolaborasi oleh dua pengamat, yakni guru kelas dan Kepala Sekolah dengan menggunakan instrumen yang meliputi : aktivitas siswa dan aktivitas guru dalam mengelola pembelajaran Up grading Learning kooperatif. 
Wahyuningsih S : Aspek Religi-Edukatif Pemahaman Ibadah Mu'amalah Melalui Penerapan Model Pembelajaran U.G.L di Kelas III SDN 064969 Kecamatan Medan Tembung Pada Semester I T.P. 2018/2019

Aktivitas Guru Dalam Pembelajaran
\begin{tabular}{|c|l|c|}
\hline No & \multicolumn{1}{|c|}{ Kategori Aktivitas Guru Agama Islam } & Kemunculan \\
\hline 1 & Menyampaikan pendahuluan & $20.05 \%$ \\
\hline 2 & Menjelaskan materi / mendemontrasikan ketrampilan & $25,72 \%$ \\
\hline 3 & Memotivasi siswa dalam kelompok kooperatif & $4,50 \%$ \\
\hline 4 & Memberi latihan terbimbing dalam kelompok kooperatif & $7,35 \%$ \\
\hline & $\begin{array}{l}\text { Memeriksa pemahaman siswa dan memberikan umpan } \\
\text { balik bagi siswa yang bertanya dan mengklarifikasi } \\
\text { materi yang kurang jelas }\end{array}$ & $22,98 \%$ \\
\hline 6 & Resitasi/tanya jawab & $7,45 \%$ \\
\hline 7 & Membantu siswa melakukan refleksi & $11,90 \%$ \\
\hline \hline
\end{tabular}

Aktivitas guru Agama Islam yang dominan adalah menjelakan materi $(25,72 \%)$, dan aktivitas guru dalam memeriksa pemahaman siswa, memberi umpan balik dan mengklarifikasi materi yang kurang jelas $(22,98 \%)$. Aktivitas pendahuluan yang muncul sebanyak $20.05 \%$. Pada tahap pendahuluan guru melakukan identifikasi pengetahuan awal siswa terhadap pokok bahasan ibadah mu'amalah. Guru Agama Islam juga memberi apersepsi berbentuk pertanyaan-pertanyaan tentang apa itu ibadah mu'amalah. Tujuan pembelajaran juga disampaikan pada tahap ini. Aktivitas guru-guru Agama Islam dalam memberi motivasi siswa dalam kelompok kooperatif sebanyak 4,28\%. Dalam hal ini guru Agama Islam memberi dorongan tentang pentingnya kerja bersama dalam kelompok dan sistem penilaian dalam pembelajaran U.G.L. . Selama siswa bekerja kooperatif guru Agama Islam selalu memberi bimbingan dalam kelompok-kelompok tersebut. Aktivitas bimbingan guru yang muncul sebanyak 7,35\%. Selama kegiatan pembelajaran kooperatit guru memberi kesempatan kepada siswa untuk bertanya, dan meminta siswa yang lain untuk menjawabnya. Guru Agama Islam mengklarifikasi pemahaman siswa yang kurang jelas. Aktivitas tanya jawab yang muncul sebanyak 7,45\%. Di akhir pembelajaran guru membantu siswa melakukan refleksi $(11,90 \%)$. Guru meminta siswa dari beberapa kelompok menyampaikan catatan kecil tentang materi yang telah diperoleh selama kegiatan pembelajaran. Refleksi yang dibuat siswa bisa berbeda, dan bagi siswa yang refleksinya kurang lengkap bisa menambah dari siswa yang lain yang lebih lengkap. 
Wahyuningsih S : Aspek Religi-Edukatif Pemahaman Ibadah Mu'amalah Melalui Penerapan Model Pembelajaran U.G.L di Kelas III SDN 064969 Kecamatan Medan Tembung Pada Semester I T.P. 2018/2019

\section{Aktivitas Siswa dalam Kegiatan Pembelajaran U.G.L. Siklus Pertama}

\begin{tabular}{|c|l|c|}
\hline No & \multicolumn{1}{|c|}{ Kategori Aktivitas Siswa } & Kemunculan \\
\hline 1 & Memperhatikan penjelasan guru & $21,54 \%$ \\
\hline 2 & Membaca/mengerjakan (buku siswa, LKS, Soal) & $7,14 \%$ \\
\hline 3 & Bekerja dalam kelompok kooperatif & $7.5 \%$ \\
\hline 4 & Mendemontrasikan kegiatan yang ada dalam LKS & $20,01 \%$ \\
\hline 5 & $\begin{array}{l}\text { Menyajikan hasil pengamatan dalam diskusi } \\
\text { kelompok kooperatif }\end{array}$ & $11,41 \%$ \\
\hline 6 & Berdiskusi/tanya jawab antara guru dan siswa & $14,74 \%$ \\
\hline 7 & Merefleksikan materi pelajaran & $12,74 \%$ \\
\hline
\end{tabular}

Sejalan dengan aktivitas guru, aktivitas dominan siswa adalah mendengarkan penjelasan guru $(21,54 \%)$ dan mendemontrasikan kegiatan yang ada pada LKS $(20,01 \%)$. Penjelasan guru menyangkut definisi dan konsep ibadah mu'amalah dengan berbagai ilustasi, guru Agama Islam berusaha memancing siswa agar mengingat pengertian tentang ibadah mu'amalah. Kemudian mengaitkan pengertian ibadah mu'amalah yang telah dikuasai oleh siswa dengan dunia nyata dalam kehidupan siswa sehari-hari. Pada saat ini, guru aktif juga menguatkan apa yang dilihat siswa. Dalam proses penguatan ini, guru juga memperkaya dengan contoh-contoh ibadah mu'amalah. Guru Agama Islam dianggap banyak menjelaskan karena setelah demontrasi dan diluar tugas LKS, guru mengaitkan ibadah mu'amalah ini dengan dunia nyata kehidupan siswa. Pada tahap ini, pengamat menilai kegiatan pembelajaran adalah guru aktif menjelaskan pada siswa aktif rnendengarkan penjelasan guru. Dari uraian ini dapat disimpulkan bahwa sebenarnya penjelasan guru yang banyak didengarkan siswa bukanlah penjelasan dari metode ceramah (langsung), melainkan perpaduan penjelasan model pembelajaran U.G.L

Berdasarkan data yang diperoleh dari siklus 1 sampai dengan siklus 3 menunjukkan adanya perubahan ke arah peningkatan aktivitas belajar siswa untuk pencapaian tujuan penelitian.

Pada siklus 1, aktivitas guru yang menonjol dalam kegiatan pembelajaran adalah menyampaikan pendahuluan (20\%) Tahap pendahuluan ini memerlukan waktu yang cukup banyak karena di dalamnya terdapat beberapa sub aktivitas operasional, yaitu (a) identifikasi kemampuan awal siswa, (b) pemberian apersepsi, (c) menyampaikan tujuan pembelajaran, dan (d) penjelasan tahapan kerja untuk tatap muka pada pertemuan itu. Langkah guru dalam menyampaikan tujuan pembelajaran siswa sudah sesuai dengan langkah-langkah model pembelajaran kooperatif yang meliputi menyampaikan tujuan pembelajaran dan memotivasi siswa. Berdasarkan prinsip pembelajaran Up grading Learning siswa dapat belajar secara paling baik dalam kontek, dalam seuatu yang terkait dengan kebutuhan yang diterapkan dalam kehidupan mereka (Nur, 2001). Untuk itu guru dalam mengaitkan pelajaran sekarang dengan sebelumnya berusaha dibuat nyata, dengan tidak mengabaikan pengetahuan awal siswa sebelumnya. Aktivitas guru yang lain adalah memeriksa pemahaman siswa dan memberi umpan balik bagi siswa yang bertanya, dan mengklarifikasi materi yang kurang jelas $(22,85 \%)$. Hanya saja dalam mengklarifikasi materi yang kurang jelas guru tampak memaksakan pemahaman kepada siswa sejalan dengan kegiatan guru dalam pembelajaran, siswa aktif dalam mendengarkan penjelasan guru $(21,42 \%)$. Penjelasan guru yang banyak didengarkan siswa bukanlah penjelasan dari metode ceramah langsung melainkan perpaduan 
Wahyuningsih S : Aspek Religi-Edukatif Pemahaman Ibadah Mu'amalah Melalui Penerapan Model Pembelajaran U.G.L di Kelas III SDN 064969 Kecamatan Medan Tembung Pada Semester I T.P. 2018/2019

penjelasan metode diskusi, demontrasi dan tanya jawab. Siswa aktif dalam mendemontrasikan kegiatan yang ada pada lembar kegiatan siswa (LKS) dengan melakukan eksperimen. Eksperimen yang dilakukan siswa termasuk dari pembelajaran Up grading Learning, yaitu mengontrol dan mengarahkan siswa menjadi pembelajar yang mandiri (self regulated-learners) dengan cara mernperkenankan siswa selalu melakukan uji coba (trial and error), sehingga pada akhirnya siswa dengan bimbingan yang sedikit dapat memproses informasi, memecahkan masalah, dan memanfaatkannya.

\section{KESIMPULAN}

Berdasarkan hasil penelitian tindakan kelas yang telah dilaksanakan, maka dapat disimpulkan bahwa :

1. Aktivitas belajar siswa dapat ditingkatkan melalui pendekatan Up grading Learning dalam pembelajaran Agama Islam di Kelas III SDN 064969 Kecamatan Medan Tembung Pada Semester 1 T.P.2018/2019 Hal ini ditunjukkan adanya kualifikasi siswa dalam belajar secara kelompok dengan predikat pada siklus $1:$ hebat sebanyak 1 kelompok, baik sebanyak 2 kelompok, dan tidak berpredikat 2 kelompok; pada siklus 2 : super sebanyak 1 kelompok, hebat sebanyak 2 kelompok, baik sebanyak 2 kelompok sedangkan pada siklus 3: super sebanyak 3 kelompok hebat sebanyak 1 kelompok, dan baik sebanyak 1 kelompok.

2. Peningkatan aktivitas belajar melalui pendekatan Up grading Learning dalam pembelajaran Agama Islam di Kelas III SDN 064969 Kecamatan Medan Tembung Pada Semester 1 T.P.2018/2019 dapat meningkatkan prestasi belajar siswa. Hal ini ditunjukkan sebesar $81.00 \%$ meningkat pada siklus 1 sebesar $68.18 \%$, siklus 2 sebesar $81.82 \%$, dan siklus 3 sebesar $90.91 \%$

\section{DAFTAR PUSTAKA}

2003, Variasi Ibadah Penambah Pundi - Pundi Amal, Artikel Penyejuk Iman, Lintas Media, Tanah Datar

Departemen Pendidikan Nasional, 2002. Manajemen Peningkatan Mutu Berbasis Sekolah: Buku 5 Pembelajaran dan Pengajaran Up Grading Learning . Jakarta : Depdiknas.

Ibrahim, Muslimin, dkk. 2000. Pembelajaran Kooperatif. Surabaya : Universitas Negeri Surabaya

Kasihani dan Astini, Up Grading Learning dalam Pembelajaran Agama Islam Makalah pada Pelatihan TOT Guru Mata Pelajaran Agama Islam dari Enam Propinsi. Di Surabaya tanggal 20 Juni s/d 6 Juli 2001.

Nurhadi, 2002. Pendekatam Up Grading Learning . Jakarta : Direktorat Pendidikan Lanjutan Pertama, Dirjen Pendidikan Dasar dan Menengah, Departemen Pendidikan Nasional.

Nur, Muhammad, 2001. Pengajaran dan pernbelajaran Up Grading Learning . Makalah pada Pelalihan TOT Guru Mata Pelajaran SLTP dan MTs Enam Propinsi. Di Surabaya tanggal 20 Juni s/d 6 Juli 2001.

Sayyid Hasan, 2002, Keunggulan Ibadah Mu'amalah Dalam Hidup, CV. Tunas Mandiri, Tanah Datar. 